\title{
On a visual phenomenon and its explanation
}

\section{William Ackroyd F.I.C.}

To cite this article: William Ackroyd F.I.C. (1879) On a visual phenomenon and its explanation, Philosophical Magazine Series 5, 8:49, 334-335, DOI: 10.1080/14786447908639692

To link to this article: http://dx.doi.org/10.1080/14786447908639692

$$
\text { 曲 Published online: } 13 \text { May } 2009 .
$$

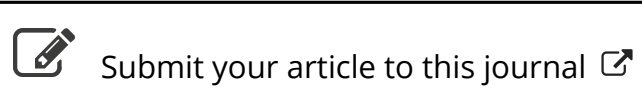

\footnotetext{
Џll Article views: 2
}

Q View related articles $\sqsubset$ 
Occultations of Stars. $\$ 14$. Observations of Eclipses from 1620 to 1724. $\$ 15$. Discussion of Deviations in the Moon's mean Motion. \$16. Motion of the Moon's node. \$17. Concluding Remarks on the Value of the Secular Acceleration deduced in this paper.

For the subjects treated in the sections above enumerated we must refer the reader to the work itself, in which will be found evidence of the skill with which the author has accomplished his task, and the results at which he has arrived. In section 15, devoted to the discussion of Deviations, the author, speaking of the cause of outstanding deviations, remarks that we may make two hypotheses:-(1) That these deviations are only apparent ones, arising from inequalities in the axial rotation of the earth. The deviation of the observed secular acceleration from the theoretical value $6^{\prime \prime} \cdot 18$ has long been attributed to a retardation of the earth's rotation; and by supposing this retardation to be a variable quantity, and indeed sometimes to change into an acceleration, we may completely account for the observed deviations. (2) We may suppose the deviations to arise from one or more inequalities of long period in the actual mean motion of the moon. On the first of these hypotheses the author says, "If it is correct, the problem of predicting the moon's motion with accuracy through long intervals of time must be regarded as hopeless, since it cannot be expected that variations in the earth's axial rotation will conform to any determinable law. Success in tracing the deviations in question to the moon itself, and to the theory of gravitation, is therefore a consummation to be hoped for."

In the last section, containing the concluding remarks on the value of the secular acceleration deduced by the author, he suggests that " either the recently accepted value of the acceleration and the usual interpretation of the ancient solar eclipses are to be radically altered, the eclipse of $-\mathbf{5 5 6}$ not having been total at Larissa, and that of -514 not having been total in Asia Minor, or the mean motion of the moon is, in the course of centuries, subjected to changes so wide that it is not possible to assign a definite value to the secular acceleration.

An important feature of this book consists of the collection of observations of eclipses and occultations (some hitherto unpublished) used by the author in his investigation. Altogether the work forms a valuable addition to the literature of the Lunar Theory.

XXXIX. Intelligence and Miscellaneous Articles.

ON A VISUAL PHENOMENON AND ITS EXPLANATION.

BY WILLIAM ACKROYD, F.I.C.

VISUAL phenomena are of general interest, and are often described but seldom explained. The phenomenon in question may be seen under the following circumstances. Face the breeze, and without winking allow a small raindrop to fall on the surface 
of the cornea, all the while keeping your gaze fixed on a lamplight some hundred feet away. As the raindrop alights on the cornea, several rings of light appear to surround the luminous source. The rings gradually contract in diameter. Explanation:-In sunshine, the moving ring crest of water produced by dropping a pebble into a still and shallow pool projects a ring of light on the bottom which gradually increases in size. The moving ring crest, by its refractive action, produces a hollow cylinder of rays of ever increasing diameter; and we see a section of it on the bottom of the pool. The raindrop falling on the cornea spreads out on its surface in several ring crests, and would similarly produce a series of outward travelling rings of light were it not for the combined action of the refractive media of the eye. Under the influence of these, two hollow cones of light are formed within the vitreous humour directly upon impact of the raindrop. The first of these has for its base a small circular area of the hind surface of the lens; and its prolongation, the second cone, has the retina for its base. As any individual ring-crest spreads out on the cornea, the first cone increases in size, the common apex advances towards the retina, and consequently the section of the second cone projected onto the retina decreases in size and appears as a contracting ring of light.Abstract of paper read in Section D, British-Association Meeting, Monday, August 25th.

\section{PRÉCIS OF A REPORT ON ELECTRIC-LIGHT EXPERIMENTS. BY L. SCHWENDLER, ESQ.*}

Mr. Schwendler said it would be impracticable to read the " Précis of Report on Electric-Light Experiments" in extenso, since it contained too many technicalities which could not easily be followed if the paper were read in the manner usual at these meetings, and that he therefore would prefer to give verbally a short account of his researches and the results obtained. $\mathrm{He}$ stated that the inquiry originated with General Strachey, who, in April 1876, recommended to the Secretary of State that a trial of illuminating Indian railway-stations by the electric light should be made. In February $1877 \mathrm{Mr}$. Schwendler was requested to institute detailed inquiries, which led him to propose that it would be advisable to first make some more experiments before a practical trial at Indian railway-stations should be attempted. The Board of Directors of the East-Indian Railway Company agreed to this, and sanctioned the necessary outlay, whatever it might come to.

The experiments made at the India Office Stores, London, terminated on the 1st November, 1878. The report, however, could not be finished in time before $\mathrm{Mr}$. Schwendler left for India; and he therefore prepared a précis-the paper before the meeting tonight. After pointing out the general results obtained, and explaining in a brief manner the three principal questions at issue,

* Read before the Asiatic Society 5th March 1879 (from the Proceedings for March). Communicated by the Author. 